\title{
Patrimonio y distopía \\ "Un viaje por el cuarto: fragmentos cortos para el encierro y el \\ distanciamiento social”
}

Fabián Andrés Llano ${ }^{1}$

\section{Introducción}

Con el decreto 521 del 8 de abril de 2020, el Gobierno Nacional extendió por catorce días más, el aislamiento preventivo o Cuarentena Nacional que irá hasta el 27 de Abril de 2020. En días pasados se conoció que la cuarentena va hasta el día 11 de Mayo del presente año. Dadas las circunstancias actuales y los aprendizajes recibidos de diferentes países en su lucha contra el coronavirus, es muy probable que este estado de emergencia se mantenga en el tiempo, quizás por uno o dos meses más. Esta situación de encerramiento ha llevado a pensar a muchas familias en la necesidad de reorganizar la vida social, cultural y económica en micro espacios que van desde los $21 \mathrm{mts}$ cuadrados a los 300 o $400 \mathrm{mts}$ cuadrados de familias de estratos 2, 3, 4, 5; por supuesto que los bogotanos de mayores ingresos económicos cómodamente pueden pasar la cuarentena en espacios de 1000 metros cuadrados y porque no decirlo, confundir esta situación de cuarentena con unas extensas vacaciones en espacios fuera de la ciudad como fincas y casas de campo.

Sin que se note mi inconformidad sobre una sociedad tan desigual como la bogotana, apelo a unos cuantos fragmentos de la literatura de viajes para hacer un poco más soportable este aislamiento preventivo. Se trata de cambiar la perspectiva del encierro a través de lo que Bernd Stigler denominó historia cultural de los viajes en y alrededor del cuarto. Pero ¿Qué significa viajar alrededor del cuarto? ¿Se trata de una introspección, una metáfora o una ficción? Tal vez tengamos que hablar de todas las anteriores o de algunas imágenes que se puedan crear o recrear por medio de los relatos. Mi pretensión no es otra que la proponer una

\footnotetext{
${ }^{1}$ Doctor en Ciencias Humanas del Patrimonio y la Cultura Universidad de Girona (España) Magister en Investigación social interdisciplinaria de la Universidad Distrital Francisco José de Caldas, Licenciado en Ciencias Sociales. Investigador Adscrito al Instituto de patrimonio Cultural de Cataluña. Se ha desempeñado como coordinador de la línea en educación, lenguaje y comunicación del doctorado educación y sociedad, Universidad de la Salle, docente de la maestría en educación de la Universidad la Gran Colombia. En la actualidad se desempeña como docente investigador del programa de Hotelería y Turismo de la Universitaria Uniagustiniana. Fabian.llano@uniagustiniana.edu.co llanofabian@ hotmail.com ID 0000-0003-2181-3476
} 
reflexión y una alternativa desde la historia cultural de Bogotá y la imaginación y la creatividad que se pueden potenciar desde el cuarto, la habitación, el apartamento o la casa.

\section{El olvido de la pandemia o la posibilidad de mundos posibles}

Para comenzar habría que romper la lógica de los sabias que... y vincular la lógica de lo que me concierne, lo que me toca a mí, o como dicen algunos jóvenes hoy día, lo mío mi pez. De qué me sirve saber lo que ocurrió hace cien años o quinientos años atrás? En lo práctico de nada. El experto en el estudio del cerebro y candidato al nobel de medicina, Rodolfo Llinás ha dicho recientemente que después de cuatro o cinco meses se olvidará lo que ocurrió, como se han olvidado todas las pandemias. Es simplemente un problema que apareció. Produce muerte, produce tristeza, produce problemas momentáneos, locales y luego desaparecen ${ }^{2}$. ¿Qué decir ante estas declaratorias? ¿Tal vez sean un tanto reduccionistas o muy realistas? Qué decir de otros intelectuales como Francesco Tonucci que se plantea la posibilidad de pensar otra escuela posible durante y después del Covid -19? O ¿de los muchos ambientalistas que se han deleitado con la presencia de animales silvestres en algunos lugares del mundo? Qué decir también de las opiniones de historiadores como Harari quien asume las diferencias de las pandemias y plantea dos frentes de combate frente al virus: o el aislamiento nacionalista o la cooperación internacional y la solidaridad.

Al parecer la represión y el olvido de este shock que ha dejado al mundo paralizado parece ser una de las opciones más deseadas, por lo menos para algunos científicos que desde el dato frio, no pueden ver que es una oportunidad sin precedentes para replantear el sentido y la dirección del mundo. Si se trata de posiciones, me encuentro en este lado de la historia que defiende la posibilidad de transformar y de crear mundos posibles, de pensar que lo que está ocurriendo es un momento histórico que va a cambiar la forma de relacionarnos, la forma en que nos educamos y la forma en que viajamos...El turismo ya no será el mismo, pero por lo pronto será conveniente mostrar otras formas de viajar: un viaje por las cercanías, un viaje

\footnotetext{
${ }^{2}$ Ver revista semana.com del 10 de Abril de 2020 entrevista a Rodolfo Llinás titulada "Volverán besos y abrazos como antes del virus" dice Llinás
} 
alrededor del cuarto, esto lo digo, sin que tenga la pretensión de convertirse en una guía de viajes o una propuesta emergente para el turismo post pandemia.

Pero ¿qué es un viaje alrededor del cuarto? Es una especie de a-alejamiento que nos aparta de un espacio habitual y lo reexplora describiéndolo al mismo tiempo (...) Estos espacios de experiencia no son imaginarios sino que describen el espacio banal de la cotidiano. Aprovechemos un poco el libro de Bernd Stigler para mirar por un momento que significa lo anterior

En la primavera de 1790, Xavier de Maistre, el hermano del teórico político conservador Joseph de Maistre, Saca el mayor provecho posible de un arresto domiciliario y realiza un viaje de 42 días por su cuarto, sobre el qué informa en un minucioso relato de viaje que se convertiría en un texto sumamente exitoso de la literatura francesa y fundaría a la vez un género propio en la literatura. (p 21)(...) las experiencias del viaje por el cuarto no sólo tienen una sujeción espacial, sino también temporal, son exploraciones de un espacio que apuntan a recuperar historias y experiencias sin ser a su vez repetibles (p 24)(...) en sus caminatas, el “viajero sedentario” (ibíd.:46) no sólo descubre la belleza práctica de los objetos cotidianos - puras cosas comunes de una casa común, como por ejemplo una cama y un sillón-, sino que también informa sobre la historia de los cuadros colgados en la habitación y sobre los descubrimientos que hace en la pequeña biblioteca. Pero de Maistre, sobre todo relata en un orden no muy riguroso, historias de la vida cotidiana -cuenta sobre su sirviente, su perro y su amada-, historias en las que, por la particular receptividad y sensibilidad que provoca la actitud del viajero, queda suspendida de manera peculiar la dicotomía de "vida cotidiana aburrida” y mundo maravilloso (Botton 2002:271). (p25)(...) El viaje alrededor del cuarto de Xavier de Maistre se puede reconocer como guía para un viaje del alma, que precisamente en la limitación espacial a las cuatro paredes propias explora el mundo interior como libertad y como autorización de sí mismo:" Me han privado recorrer una ciudad, un punto; pero me han dejado el universo entero: la inmensidad y la eternidad están a mis órdenes" (ibíd.:83 (141)). p26 
Múltiples pueden ser las razones para un viaje en el cuarto: enfermedades o accidentes, falta de dinero o agorafobia, aburrimiento o melancolía, eros pedagógico o bibliofilia, sed, como en aquel viaje que lleva al sótano propio para vaciar allí una botella tras otra, O sencillamente las ganas de seguir el ejemplo de Xavier de Maistre. (p49)(...) Desde fines del siglo XVIII hasta muy avanzado el siglo XIX, surge un gran número de viajes en miniatura en los que no se transpone el umbral de una habitación o casa, o los límites de una ciudad: se viaja por los bolsillos del pantalón, por la tienda de campaña, propia o -algo es algo-por una gran ciudad como Paris, que como dice Arsene Houssaye, apasionado viajero lugares lejanos, sigue siendo un mundo desconocido hasta para el propio parisino; o alli en Paris se elige viajar únicamente por el Palaisse Royal, que demanda el solo todo un viaje (Houssaye, 1885:230). P 51

En esta mezcla de fragmentos y de ideas que, confunden el mundo exterior con el imaginario, también se puede aceptar fácilmente algunas referencias sobre Bogotá, desde una perspectiva de historia cultural:

Los encuentros y las tertulias bogotanas que se llevaron a cabo al interior de algunas viviendas de la elite bogotana fortalecieron una regularidad y una asiduidad, que bien podría compararse con las dinámicas de los salones aristocráticos del siglo XVIII. No obstante, esta dinámica cultural que se desarrolló al interior de las viviendas, especialmente en el salón principal de la visita santafereña, conocida como la sala de la casa, no contó con el mecenazgo de una dama patrocinadora de las letras, ni con la visita de personajes con grandes ambiciones literarias. Como espacio de conversación y de rituales de conversión de unos patrones de vida, la sala, se convierte para el caso bogotano, en uno de los escenarios más propensos a la aceptación y legitimación social.

A propósito de las tertulias y bailes aristocráticos, el centro de la atención no era de ninguna manera el té o el café, sino el chocolate. Esta bebida emblemática reunía a diferentes personajes prestantes de la ciudad, en torno a la tertulia santafereña 
En la capital, en las ciudades de provincia, alrededor de la mesa, frente a las tazas de chocolate- el café vendría más tarde- canónigos, notables, damas sensibles, políticos, científicos, se reúnen en las llamadas "tertulias", que se institucionalizan con nombres llenos de sabor a época: "eutropélica", "del buen gusto", "científica." Esta última alcanza importancia, ya que fue presidida por el fundamental magisterio del sabio gaditano José Celestino Mutis, que congregó a jóvenes en quienes había logrado despertar el interés por las ciencias y la política desde hace años (Camacho: 1989: 323) 3.

Vale la pena aclarar que, tanto la fracción de la elite que perseguía la introducción de prácticas liberales y liberadoras de la vida colonial y las facciones que intentaban esa misma modernización desde unas bases más tradicionales, perseguían la adopción de patrones de distinción. La mejor impresión que la elite podía dar sobre su condición distinguida era hacer alarde de patrones europeos incorporados en los famosos bailes de salón. Cuando se hizo evidente la llegada de viajeros extranjeros al país hacia 1820, las prácticas de sociabilidad frente a estos personajes que por lo general desempeñaban cargos diplomáticos, científicos o tenían pretensiones comerciales, era por supuesto invitarlos a estas reuniones exclusivas para lograr un posicionamiento cultural que demostrará cercanía con los procesos civilizatorios.

Vale la pena anotar que algunas referencias de la aparición de unas prácticas culturales asociadas al consumo de café en nuestro país, se vincularon directamente con la actividad aristocrática, que más que permitir la disposición de un lugar donde los escritores y artistas pudieran juntarse de acuerdo a sus afinidades dentro de una institución como el salón, se dispuso más bien como una práctica cerrada y poco difundida. De acuerdo con Martínez Carreño (1990) una de las pocas evidencias de la presencia del café en la vida social en esta época, se vinculó directamente a las actividades restringidas de la aristocracia del siglo XVIII. Por ejemplo, en el inventario de bienes de El virrey Solís, hecho con motivo de su ingreso a la orden franciscana en 1761 se percibió la enorme diferencia numérica entre utilería para servir café y chocolate. Esto parece indicar que el primero era apenas una moda incipiente y tal vez un tanto exótica (p24). Muy asociada a la tradición de los refrescos y las

\footnotetext{
${ }^{3}$ Este auge de las ciencias impulsadas a través de las tertulias, lograron publicar por medio de la dirección de Caldas el Semanario. Aquellos literatos pretendieron siempre exhibirse formados en los moldes del clasicismo; invadieron por primera vez con seriedad y éxito el campo de las ciencias físicas, cultivando in pectore el amor a la política, en cuyas teorías y problemas habían de ensayarse después con tanto ardor (Laverde: 1963)
} 
bebidas exóticas, todo parece revelar, que como práctica cultural no se había extendido a las diferentes clases sociales ${ }^{4}$. Mucho más adelante en la segunda mitad del siglo XIX aparece otra referencia a la aparición de los cafés en el espacio social y urbano bogotano.

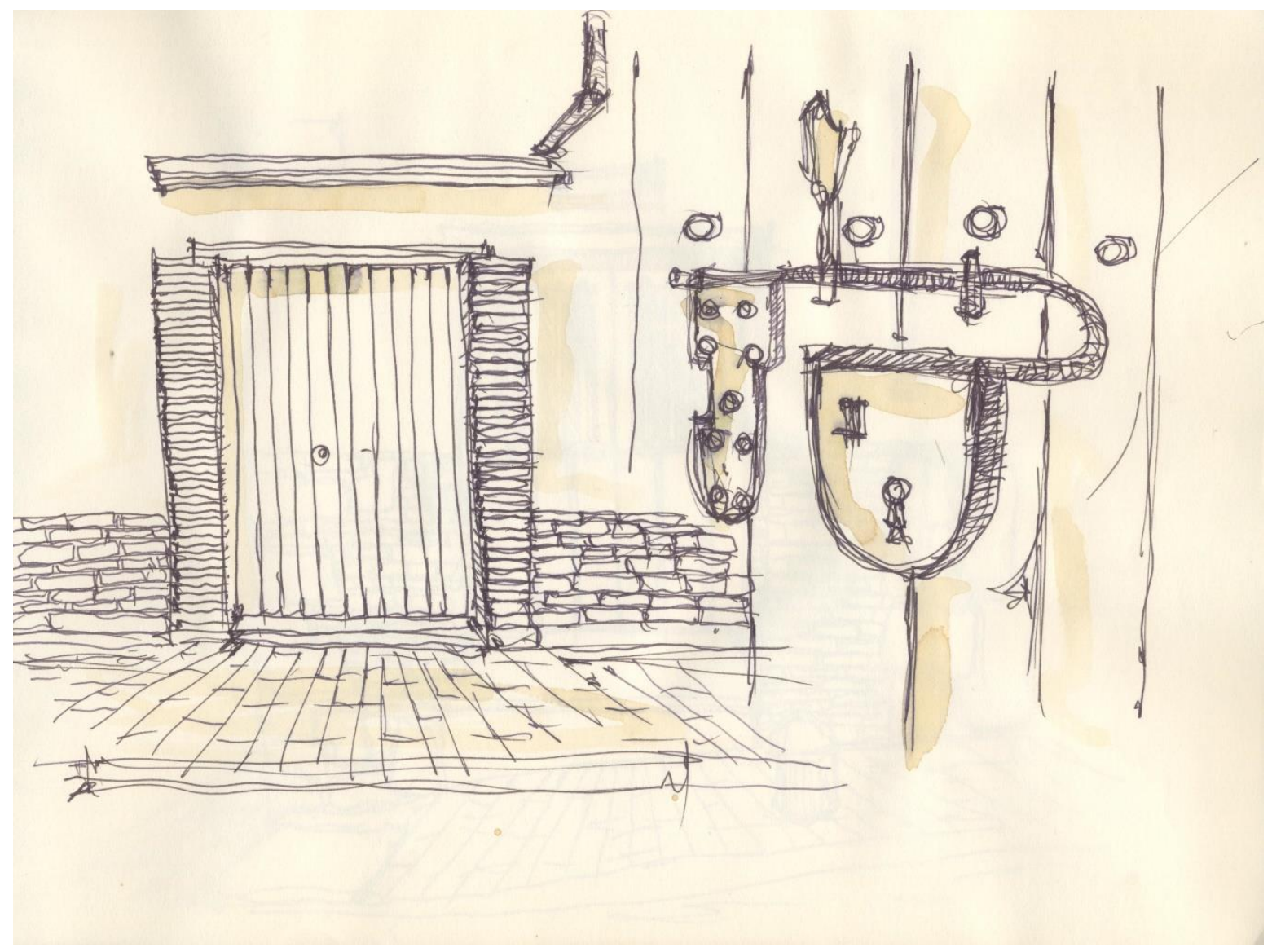

Ilustración 1. Centro histórico de Bogotá. Ilustración Arquitecto Miguel Payán Aparicio.

Lo que más bien ocurrió en el espacio social y urbano bogotano fue la cada vez más generalizada visita santafereña para reafirmar las diferencias. De acuerdo con Serna (2001) las visitas, eventos ampliamente reconocidos en el mundo santafereño del siglo XIX, implicaban una particular atención en tanto era a través de ellas que se reafirmaban las formas legítimas de pertenencia a las diferentes posiciones del espacio social. El hogar se convertía en el espacio predilecto para ejercer las actividades de lo público, ante la inexistencia de

\footnotetext{
${ }^{4}$ Las clases sociales más que vivir en familiaridad, estaban sometidas a fuertes diferenciaciones que los distanciaban de ese ideal de igualdad introducido por algunos miembros de la elite en sus viajes a Paris. De acuerdo con Mörner (1969) en el siglo XVIII, el prejuicio racial en Hispanoamérica, como en todas partes en la misma época, estaba creciendo obviamente. Los párrocos generalmente llevaban tres registros separados, uno para los españoles, otro para las castas de mezclas, y un tercero para los indios(pp63,64)
} 
lugares propicios para exaltar las diferencias. De esta manera, el papel de los intelectuales y la existencia de espacios para interlocutar, era más bien reducido a la vida privada

En este panorama eran las residencias, la disposición privada de los hogares, uno de los lugares que definían de manera determinante la pertenencia a una de las jerarquías del espacio social. En realidad, era tan frecuente la proximidad entre las clases sociales que se dio el caso en el que las casas de dos pisos eran subdivididas, conviviendo en el mismo inmueble gentes aristocráticas y acaudaladas en el segundo piso, con moradores paupérrimos en el primero. [Martínez citado por Peralta: 1995:33] los criterios de distinción, no recaían en las fachadas de estas casas sino al interior de ella, donde se constituía en un centro social por excelencia, a través de las fiestas y celebraciones privadas que eran las actividades para introducir los nuevos sentidos legítimos de la existencia, cumpliendo de esta manera la labor de dar a conocer las nuevas divisiones del mundo social.

En este sentido, la dinámica que se establecía en torno al interior de las casas de la elite bogotana, mostraron una mayor incidencia de los bienes de consumo que vinculaban a estas posiciones con el universo de lo público, transformando de esta forma, los parámetros de lo público y lo privado. Como la vida social se desarrollaba al interior de las casas, específicamente en la sala, los gustos legítimos de la existencia se manifestaban en la práctica de la ostentación y el lujo

"El lujo en la sala, aunque expresión de una actitud esnobista, también estaba relacionado con un aumento en el bienestar económico de un sector importante de la capital. El caudal promedio de los inventarios entre 1820 y 1846 era de $\$ 40.047 .46$. Esta cifra resulto casi duplicada entre 18541882 [\$75.292.67]. El valor de la sala, por su parte paso de un promedio de $\$ 331.93$ en el primer periodo mencionado, a \$ 1.076.5 en el segundo periodo, mostrando un aumento de 3.24 veces. En este sentido la sala debía tener: alfombra y papel colgado; los muebles debían estar acorde en diseño, tamaño, tipo de madera y forros, es decir, en estilo; debían estar a la moda y por lo mismo debían ser importados; no debían disfrazar la madera barnizándola; la sala no debía exhibir muebles en mal estado, asientos de guadamacil, ni enseres que - como el ropero y la cómoda - no correspondieran al lugar; desde la sala no 
debía verse el interior de la alcoba; el salón debía exhibir cielo raso del que debía colgar una sola lámpara [y no bambas de vidrio]” (Lara,1997 p.102)

Desde 1846, época, en la cual se fundó la sociedad filarmónica, por José Caicedo Rojas, se difundió el interés por la música para piano avivado por el mayor número de estos instrumentos que se veían en las casas de las elites. Aunque el piano importado seguía siendo costoso [\$ 1.200], David McCormick tenía en Bogotá una fábrica de pianos desde 1837, lo que ayudo un poco a su popularización (cfr. Lara, 1997, p186)

En el interior de las casas el lujo es extraordinario y causa espanto al extranjero, cuando se considera que la mayor parte de los ricos muebles, cuadros y espejos que adornan las casas de los ricachos de Bogotá, son traídos a hombros de hombres desde honda. El clima exige el uso generalizado de la alfombra, y con frecuencia pise ricos tapetes aterciopelados de las fábricas de Francia e Inglaterra. Los corredores y terrazas de los claustros están todos forrados de estera común, fabricada en el país; el gusto por la pintura al óleo es general; y es muy rara la casa de una persona acomodada donde no exista el piano, aunque el transporte de uno de estos instrumentos desde Honda a Bogotá cueste doscientos cincuenta pesos (Lisboa, 1866/1984 p.214)

Ahora bien, las visitas y la práctica de evidenciar estos lujos al interior de las casas, predominarían hasta las últimas décadas del siglo XIX. Estos encuentros de la elite bogotana fueron narrados por Miguel Cané ministro plenipotenciario de Argentina, quién estando de visita en nuestra capital para el año de 1881, resaltaba el carácter de las fiestas en Bogotá:

"La vida social es muy activa con respecto a las fiestas... [D]e tiempo en tiempo un gran baile, tan lujoso y tan brillante como en cualquier capital europea ó entre nosotros. [M]iraba aquel mobiliario lujoso, los espesos tapices, el piano de cola Ehrard ó Chickering y sobre todo los inmensos espejos, de lujosos marcos dorados que cubrían las paredes..." (Cané: 1901/1992: 160)

Así pues, en un espacio social y urbano caracterizado para esta primera mitad del siglo XIX como un espacio limitado en apertura pública con una dinámica cultural que, en 
vez de proyectarse a la vida urbana, fortaleció su ensimismamiento en el interior de las viviendas, se hizo importante, entonces, la promoción de bailes y encuentros bajo un carácter mucho más íntimo y excluyente. Vale la pena decir que estas prácticas ya estaban afianzadas desde comienzos de siglo. En su diario el 19 de julio de 1815 José María Caballero resaltaba lo siguiente:

Al baile asistieron 175 señoras carracas y adictas al gobierno (de criterio centralista) y otros tantos hombres de la misma opinión...en seguida se sirvió un refresco costeado por el Estado, que importó \$250, con un ambigú que se dio a las 12 de la noche. ¡Bueno ¡me gusta que coman, bailen y se diviertan a costillas ajenas. Que sabroso será. ¡Oh, quien pudiera, pero no con lo ajeno ¡(Martínez Carreño, 1990, p35).

De acuerdo con Llano (2012) en estas reuniones sociales de salón, era común observar manifestaciones de la cultura francesa a través de expresiones como à la Française, que simbolizaba en cierto sentido, una representación de las mujeres que lucían vestido y tocado a la moda francesa. Esta dinámica era corroborada por el diplomático sueco August Gosselman, quien estaba complacido que en estas tierras se vieran costumbres similares a las europeas con un ritual de inspiración europea:

En la manera de conducirlo, en la decoración del salón, en el vestido y arreglo de los asistentes, en los modales, en la música, en los bailes y en la manera de servir la comida. En efecto la elite había adoptado los rituales franceses a finales del siglo XVIII, a través de la ideología ilustrada de los borbones; sin embargo, en las primeras décadas de vida Republicana seguían conservándolos (Gosselman, 1825).

Finalmente, a pesar de introducir prácticas y estilos de vida afrancesados, la vida social al interior de las viviendas encerraba todo un universo social y simbólico. Esta experiencia espacial resultaba ser todo un viaje de descubrimiento de la sociedad capitalina al interior de un salón. En la medida en que el mismo espacio urbano bogotano tampoco daba muestras de un cambio que permitiera fortalecer la vida pública, esta práctica se mantuvo en el tiempo negando la mirada del espacio exterior con las historias que pudieran haberse 
contado desde la ventana y desde los cafés, que valga decir no existieron para este momento como espacios de sociabilidad.

\section{Referencias}

Llano, F. (2019). La superación del mito de la Atenas suramericana: los cafés como espacios de la producción cultural (Bogotá 1880-1930) en: Empreu aquest identificador per citar en o enllaçar aquesta tesi:http://hdl.handle.net/10803/667757

Stiegler, B. (2012). La quietud en movimiento una breve historia cultural de los viajes en y alrededor del cuarto. Buenos Aires, editorial Paidós 